\title{
Teachers and learners in a time of big data
}

\author{
Rachel Buchanan \\ The University of Newcastle, ORCID 0000-0003-3594-1110 \\ Rachel.Buchanan@newcastle.edu.au \\ Amy McPherson \\ Australian Catholic University, ORCID 0000-0003-3685-1547
}

Amy.McPherson@acu.edu.au

\begin{abstract}
Policy and technological transformation have coalesced to usher in massive changes to educational systems over the past two decades. Teachers' roles, subjectivities and professional identities have been subject to sweeping changes enabled by sophisticated forms of governance. Simultaneously, students have been recast as 'learners'; like teachers, learners have become subject to new forms of governance, through technological surveillance and datafication. This paper focuses on the intersection of the metrics driven approach to education and the political as a way to re-think the future of schooling in more explicitly philosophical terms. This exploration starts with a critical examination of constructions of teachers, learners and the digital data-driven educational culture in order to explicate the futures being generated. The trajectory of this future is explored through reference to the technoeducational models currently being developed in Silicon Valley. Drawing on Deleuze's notion of control societies we contribute to the ongoing philosophical investigation of the datafication of education; a necessary discussion if we are to explore the future implications of schooling in a technologically saturated world. We present consideration of the past, present and future, as three ways of considering alternatives to a datafied education system. Alternative conceptualisations of the future of schooling are possible which offer ways of understanding and politicising what happens when we impose data-driven accountabilities into people's lives.
\end{abstract}




\section{Key words}

big data, control society, learning analytics, students, teachers

\section{Introduction}

Futures are not inevitable. They are imagined and created, but always with the legacy of the past bound into their fabric. (Robertson 2005, p.

In Australia, the last two decades of policy change has resulted in a re-configuring of the education system. Control has tilted; with previously state-based control over the education profession now exercised nationally in terms of the curriculum, professional standards for teachers and principals, and in the administration and publication of the results of the NAPLAN standardised tests (Savage 2016). The changes in the Australian system reflect broader global shifts, in which similar patterns can be discerned in education systems internationally (Rizvi \& Lingard 2010). These changes include: a loss of teacher autonomy, a push for evidence-based education policy, the increased use of standardised testing, rising levels of corporate involvement in schooling, and a resolute push for the technologisation of education. While such issues can productively be examined from policy and empirical perspectives, we take a different tack and will be exploring one salient feature of these trends, the datification of education, from a philosophical vantage in order to consider the future of schooling.

Policy shifts have coalesced with technological developments to reshape the educational system. Teachers' roles, subjectivities and professional identities have been subject to sweeping changes enabled by sophisticated forms of governance (Clarke \& Moore 2013). Simultaneously, students have been recast as 'learners' (Biesta 2010). Like teachers, learners have become subject to new forms of governance through technological surveillance and datafication (Lupton \& Williamson 2017). This paper provides a philosophical exploration of the intersection of the metrics-driven approach to education and the political as a way to re-think the future of schooling. The shifts we describe here have been detailed with greater focus elsewhere by the variety of authors we draw upon to make our case. Our purpose in pulling together this literature is to highlight the trends evident in educational change, in order to question the foundations presently being laid for the 
future of schooling. The trajectory of this future is explored through reference to Deleuze's (1992) notion of control societies and the techno-educational models currently being developed in Silicon Valley (Williamson 2017a). We conclude our philosophical exploration of the future implications of schooling in a datafied education system with the alternative perspectives offered by consideration of the past, present and future.

\section{Accounting for the 'unaccountable teacher'}

This section of the paper sketches out the process of being a teacher in the context of 'datafication' (Mayer-Schoenberger \& Cukier 2013). Our starting point for this discussion of datafication and teacher subjectification is that these emerging identities are not 'natural'. Rather, these identities must be understood in the context of global neoliberal education policy-making, a powerful accountability agenda and the corporatisation of education. As Williamson states: 'the technologies of digital education governance are socially, politically and economically produced, and also socially, politically and economically productive' (2016a, p. 6). The now ubiquitous use of big data technologies in educational governance, from the macro level of systems to the micro level of everyday classroom life, are driving fundamental transformations of teacher professional identity that require consideration. This section will begin to explore how data, numbers and metrics - as well as the associated practices of evidencing, auditing, measuring, and monitoring-impacts the teaching self. We are particularly interested in highlighting how the 'enumerative accountability' (Lewis \& Holloway 2018, p, 2) generated by data works to shape the subjects teachers become.

Williamson (2016b) alerts us to some of the modes and methods of digitising educational governance. He describes how from the global or supranational, national, and local levels, we see big data, database architectures, datasets, codes, algorithms, analytic packages, and data dashboards-just some of the emerging technologies that are subjectifying the 'quantified teacher'. Lewis and Holloway (2018) point us toward ways in which 'data-driven practices and logics have come to reshape the possibilities for what the teaching profession and professional are and can be' (p. 1). Consisting of both effective and affective dimensions (Lewis \& Holloway, 2018), the subjectification of teachers through data produces a quantifiable version of the teaching self, able be viewed through patterns and trends in data, where educators are not only, 'disassembled into digital bits and data points 
that are amenable to new forms of measurement' (Williamson 2016a, p. 5), but then able 'to be steered in certain data-centric ways' (Lewis \& Holloway 2018, p. 3).

The various ways such data and its generation, analysis, representation and dissemination has been experienced by teachers has been subject to a growing number of studies (Thompson \& Cook 2014). The process of converting teaching into digital data which can be analysed and used to inform, track, assess and even predict individual teaching and systems-based interventions and programs, have been shown to be part of contemporary techniques of governance. Yet this use of data is problematic in many respects. Large-scale data collections generated through standardised testing regimes at the global and national level have been shown to 'steer at a distance'; while the continuous collection and use of evidence generated through practice adds to an ongoing program of self-evaluation (Sellar \& Lingard 2014). Being 'steered at a distance' (Ball 1998) through datafication thus involves processes of subjectification on the part of teachers, where changes and modification to teaching and teachers are facilitated by an unremitting management of the self. This process has teachers striving to make themselves 'calculable rather than memorable' (Ball 2012, p. 17).

More recent analysis has raised the possibilities of using large-scale data prediction to monitor teaching propensities, 'to move analytics from hindsight to foresight, from description to prediction through a diagnosis of what to change in teaching methods and organizations' (De Rosa 2017, p. 69). The implications of such shifts in relation to the governance agenda, however, raises interesting questions. Edwards and Fenwick (2016) ask: 'if predictive analytics become the basis of decision making, rather than professional judgement and discretion, who (or what) is legally and ethically responsible when things go wrong?' (p. 145).

Emotions have also been documented as playing a vital role in how teachers engage with subjectification through data. Functioning through processes of selfmanagement, datafying teachers appear to operate through an intensification of the affective engagement with data (Sellar 2015). Roberts-Holmes and Bradbury (2016), for example, have shown how, 'Data packs were used to compare and rank, locally and nationally, with the intention of "naming and shaming"' (p. 123) where teachers 'found their working lives constrained by exhaustive demands for the production and analysis of data' (2016, p. 121). Stevenson (2017) identified a 'growing sense of alienation as teachers are compelled to focus on outputs over individuals' (p. 538). 
Rather than a rational and reasoned response to data, much of the current datafication requires an unthinking engagement from teachers. As noted by Selwyn, Nemorin and Johnson (2017), teachers in their study were required only to input data, as 'most decision-making around these aggregated data was conducted by software' (p. 395) through data infrastructures that are 'still very opaque' (Hartong' 2018, p. 146). At present, little has been done to reconceptualise forms of reflexive agency and generate collective efforts to create alternatives for how (datafied) teachers can use data for their own purposes or on their own terms. It could be argued that, by design, teachers are not meant to use such data for their own purposes as the political intent behind the use of such data is to account for the 'unaccountable' teacher (Thompson \& Cook 2014), a motive reflective of the suspicion that the teaching profession is held in by policy makers (Connell 2009). If teachers can't be made 'accountable', datafication makes them countable, measurable and able to be ranked. And not just through data generated about their students, but against the data that they themselves must produce about their professional development. Accreditation against the Australian Professional Standards for Teachers requires teachers to not only demonstrate their teaching via their students' learning, but also their own ongoing professional learning and development must be documented and assessed; a process that codifies and domesticates the profession (Clarke \& Moore 2013). We have indicated how teachers' documentation of their own practice and measurement of their students' performance subjects them to increasingly sophisticated processes of datafication, we now turn to an examination of the datafication of students.

\section{Datafication of the learner}

First they said they needed data about the children

to find out what they're learning. Then they said they needed data about the children to make sure they are learning. Then the children only learnt what could be turned into data. Then the children became data. 
While the use of standardised testing has increased in many education jurisdictions, the Australian approach reflects the idiosyncrasies of its political system. The National Assessment Program - Literacy and Numeracy (NAPLAN) test is administered nationally to students in years 3, 5, 7 and 9 and putatively tests basic literacy and numeracy skills. The results are publicly displayed on the 'My School' website, which effectively elevates NAPLAN into a high-stakes testing regime as the results publicly display schools as performing above, on, or below average. This use of NAPLAN data reflects a change in the prevailing 'logic of teaching' (Thompson \& Cook 2014, p. 129) in which data is elevated above other methods of arbitrating teaching and learning. Thompson and Cook (2014) argue that the primary justification for the introduction of NAPLAN is 'to constitute a mechanism that measures, and therefore produces, "good teaching"' (p. 130). The teaching produced via this mechanism of measurement reduces student achievement to a crude test result.

The logic of ubiquitous data collection reflects what Biesta $(2010,2012)$ has called the 'learnification' of education, whereby the multiple potential purposes of education became subsumed by a focus on learning. Measurements of learning via the collection of data become a proxy indicator for the quality of education. Biesta's work (to which we will return later in our discussion) makes clear that learnification represents an impoverished vision of education. The point here, however, is to highlight the relationships amongst this myopic focus on learning, efforts to measure this learning, and the frenetic data collection activities taking place in schools.

Lupton and Williamson (2017) inform us that this use of standardised testing data is not the only way in which students are 'datafied'; various methods are used to surveil and monitor factors as diverse as appearance, growth, development, health, relationships, moods, behavior and educational achievement. Data are collected and stored on proprietary platforms that have a commercial motive for their involvement in education (Williamson 2017a). While schools have long been a location in which children have been closely monitored by educational and government agencies (in terms of health, well-being, developmental and educational progress), what is new is the degree to which data can be collected, combined and compared against other data sources. This big data generation and collection has been termed 'dataveillance', a process that reconfigures students as 'digital data assemblages' (Lupton 2016). 
Dataveillance can be achieved, for example, via wearable devices which offer the opportunity to measure students' physical activity. Lupton and Williamson (2017) describe 'LeapFrog LeapBand ${ }^{\mathrm{TM}}$ - a digital wristband connected to an app that encourages children to be physically active in return for providing them with the opportunity to care for virtual pets' (p. 784). In another example, students are expected to wear Fitbit activity trackers, and to engage with their own activity data so that they are motivated to further improve their fitness (Lee \& Drake 2013; Lee, Drake \& Williamson 2015). Lupton and Williamson (2017) term wearable technologies 'body surveillance devices' and describe how these 'project an optimal form of fitness and wellbeing into a kind of pleasurable body pedagogy that conveys normal expectations and moral codes about health' (p.784).

Learning analytics platforms are increasingly being used in schools. These are designed to 'mine data about learners as they go about educational tasks and activities in real time and to provide automated predictions of future progress that can be used as the basis for intervention and pre-emption' (Lupton \& Williamson 2017, p. 785). The use of such platforms is based on the assumption that 'more and better data improves teaching and learning processes' (Thompson \& Cook 2017, p. 743). The purpose of learning analytics is to use adaptive algorithmic determinations of students' progress to generate predictive data patterns that suggest interventions for the personalisation of learning activities so that students will be motivated to invest greater effort into their own education (Thompson \& Cook 2017).

It is not just students' educational progress and physical activity that is routinely monitored. Lupton and Williamson (2017) describe the situation in the UK where most 'schools have CCTV cameras that track students, and many use biometric tracking technologies such as radio-frequency identification (RFID) chips in badges or school uniforms and fingerprint or retina scanning to identify children and monitor their movements and purchases at school canteens' (p. 784). Additionally, in many education systems, children's educational histories are recorded in databases, which can be linked with other datasets so that individual students' educational progress can be tracked and monitored over the course of their entire education (Lupton \& Williamson 2017). Increasingly sophisticated programs allow for the collection and combination of various types of information on students; not just educational results and progress, but on the minutiae of daily student life: behavior; demerits; uniform infractions; homework, etc.; combining to create detailed datadriven histories of students' educational life-courses. 
The examples detailed above show how big data allows for the continuous monitoring of students in a multitude of ways. Students' educational progression from preschool to further and higher education can be tracked; their physical activity, use of digital devices, social media, and physical locations can be recorded in perpetuity as well as tracked in real time. The ready availability of this wealth of data has generated new norms against which students are measured, new moral codes and social expectations, and defines students against data-derived categories. As many of the platforms used to collect this data are being developed in Silicon Valley, we now turn our attention there in order to explore the educational futures under construction.

\section{An educational future designed in Silicon Valley}

Silicon Valley is both a physical place and an idea. Geographically, it is a place in Northern California, located around the Santa Clara Valley. Symbolically it represents a 'technopolis' (Duff 2016) - a technological city whose inhabitants' success and wealth has been built on a mixture of high-end technology, innovation, venture capital, and social media. Silicon Valley functions as an inspirationperpetuating the article of faith that technological solutions can be found to all social problems if we approach them with a mixture of the right work ethic, a belief in innovation, and a combination of capitalist and philanthropic ideals (Williamson 2017a). Williamson argues that because of the profits to be made in education, 'venture philanthropists' have been investing in education. The innovations being developed include: homeschooling approaches based around 'hackerspaces' where children are able to pursue their (technological) interests; 'start-up' schools where computer programs are used to personalise learning and administration; 'teen technorati' programs where young people are encouraged to drop out of school/college to undertake apprenticeships in Silicon Valley corporations; and the development of self-help courses based on psychological self-improvement, designed for the perpetual improvement of human capital (see Williamson 2017a, p. 266). While the latter is based around the pre-existing notion of the entrepreneurial self, inherent in neoliberal ideology, what's new is the app-based gamified platforms designed on psychological principles of persuasion that are being used to deliver such courses.

These 'disruptive innovations' reduce the need for teachers in schooling, make those who develop the educational technologies instrumental in education, and shift 
public education from a democratic controlled system to one designed and run by corporations. Williamson states:

Although venture philanthropies have long sought to interfere in public education through charter schools, the new Silicon Valley venture philanthropists are seeking more overtly computational models of education reform which utilize the technical expertise of Silicon Valley itself to design new software systems and technological fixes for insertion into the institutions of education. (2017a, p. 226)

Such a move positions these venture philanthropists (who are seeking to reproduce their centrality in the technological economy in global education) as educational reformers; effectively making Silicon Valley corporations 'shadow education ministries' (Selwyn 2016, p. 131). These techno-educational reformation efforts are underpinned by a particular mindset, one which seeks the creation of 'entrepreneurial individuals' (Williamson 2017a, p. 269), modelled on the would-be reformers themselves with their 'programmer mindset' who embody 'Californian capitalism' (Selwyn 2016, pp. 114-115) and develop and export 'disruptive' educational technologies. ClassDojo provides an example of such a technology.

ClassDojo is a product of Silicon Valley and is currently one of the world's most successful educational technologies (Williamson 2017b). The ClassDojo website (https://www.classdojo.com/about/) notes the popularity of the application, proclaiming that it is 'actively used in $90 \%$ of K-8 schools in the US, and in over 180 countries'. ClassDojo is a free app for teachers. It allows them to award points to students for positive behavior and participation in the classroom, as well as facilitate communication and information sharing with parents. The popularity of ClassDojo can be explained by its ability to provide 'measurable evidence of progress on the development of students' non-academic learning' (Williamson 2017b, p. 442), that is, it measures qualities traditionally difficult to quantify. Williamson describes ClassDojo as 'a persuasive technology' designed to routinize particular social and learning behaviours through reinforcement (p. 448). While ClassDojo gamifies the classroom with its customisable avatars, leaderboards and rewards for positive behaviour, it can be used to give warnings and deduct points. 'ClassDojo turns classroom behaviour into a quantifiable source of value for children to use a public display of their compliance with classroom norms and expectations' (Williamson $2017 \mathrm{~b}, \mathrm{p}$. 444). The app encourages children to measure and value themselves and their classmates via the visual representation of their behavioural data, and it 
reaches outside of school and into students' homes when used to communicate with parents. Problematic aspects of ClassDojo also include its use of virtual badges for obedience, and its encouragement of competition and group surveillance. Williamson (2017b) critiques the app for making students complicit in their own monitoring and labelling, calling it 'a technology of psycho-compulsion and behavior modification' (p. 450).

While behavioural modification is not a new feature of schooling, the corporeal focused disciplinary technologies (such as the classroom, timetables, uniforms, etc.) of education are being supplemented by digital technologies such as ClassDojo that collect data about students' emotional/psychological, and cognitive/neurological states. Such data is not merely gathering information but is also governing students' bodies, emotions and thinking. This shift from the primacy of controlling the body, to more data-derived means of control can be productively explored using Deleuze's (1992) conceptualisation of control societies. Silicon Valley is seeking the development of further 'innovative' digital technologies that can shift more educational authority (and control over students' minds and emotions) into the hands of the programmers. Such a move could potentially render teachers redundant and further subject students to datafication. School students around the globe, regardless of the education system in which they are physically located, could be learning from the same apps or techno-education programs. These Silicon Valley technologies would determine what, when, and how students learn-with curriculum and assessment determined algorithmically based on students' prior engagement and achievement. Technologies such as learning analytics platforms 'displace the embodied expert judgement of the teacher to the disembodied pattern detection of data analytics algorithms', risking students' opportunities being narrowed by the assumptions encoded in the algorithmic logic (Lupton \& Williamson 2017, p. 8). In this potential educational future, not only are teachers bypassed (with their experience and professional judgement removed from the learning setting) but local and national educational systems lose authority to those who design such technologies (Williamson 2016b).

\section{From discipline to control: Reflections on the past, present and future}

In his essay 'Postscript on societies of control' Gilles Deleuze (1992) provides an account of power that builds upon Foucault's work. Summarising Foucault's analysis of disciplinary societies and the attendant modes of power, Deleuze 
describes a shift to what he terms 'societies of control'. Deleuze's description of control societies is provided by contrasting control with discipline. Disciplinary societies exercise power over individuals' bodies, corralling them together in enclosures such as schools, hospitals, prisons and factories. Lives are lived in a succession of closed environments; the household, school, barracks. In societies of control, corporeal control is replaced with affective control; control of people within spaces is replaced by monitoring their movements - 'what counts is not the barrier but the computer that tracks each person's position-licit or illicit-and effects a universal modulation' (Deleuze 1992, p. 7). The methods of disciplinary societies have not disappeared but rather these have become less important as they have been supplanted by new methods of 'free-floating control' (p. 4) offered by the computer, the technology that for Deleuze expresses the social form of societies of control.

In such societies, with the measurement, monitoring and assessment offered by technology, 'individuals have become "dividuals," and masses, samples, data, markets, or "banks"' (p. 5). While discipline was exercised over long durations it was finite and discontinuous, whereas 'control is short-term and of rapid rates of turnover, but also continuous and without limit' (Deleuze 1992, p. 6). The shift from discipline to control has implications for education 'just as the corporation replaces the factory, perpetual training tends to replace the school, and continuous control to replace the examination' (p. 5). In considering the datafication of students and teachers, it is possible to discern the operation of modes of control as explicated by Deleuze. An example is the way in which contemporary 'practices inscribe children within an ever-intensifying network of visibility, surveillance and normalization, in which their behaviours and bodies are continually judged and compared with others' (Lupton \& Williamson 2017, p. 7). The operation of such technologies seeks to shape subjectivities so that people seek to constantly improve themselves.

We have here briefly sketched out the concept of control societies, but others have used Deleuze's work to more comprehensively analyse practices in education and technology (see Poster \& Savat 2009; Thompson 2017; Thompson \& Cook 2017). What should be clear is that the emergent policies, practices and products are bringing changes to the subjectivities of teachers and the conceptualisation of students in line with the modalities of control described by Deleuze. Teachers are becoming administrators of technological products and inculpated in the process of data collection. This work is being shaped by the educational technologies in use, and by the designers and proprietors of such products. This situation has developed, partially, via policy which seeks to improve educational processes. Given that 
'educational policy always sits at the intersection of the past, present and future, with the latter often expressed in policy texts as an imagined desired future' (Rizvi \& Lingard 2010, p. xi) we need to take a more deliberate approach to the future, consider the present, and reflect on the past. Through our discussion of the past, present and future we offer three ways to consider alternatives to the datafication of education. The first is to look to the past (Connell 2009), the second is to reconsider the present purposes of education (Biesta 2010), and thirdly to leave the future behind (Sellar 2016).

Connell $(2009,2012)$ reminds us to look to the past, not wearing the rose coloured glasses of nostalgia, but through the hindsight offered by history and informed by the research of the social sciences. With an appraisal of the past we can remind ourselves that the future is not inevitable - the future, like what has gone before, is a product of human action and agency. We can unmake what has been made, knock down and rebuild that what we have already built. Mass literacy, the global shift in the education of women and girls, and the reduction of socio-economic inequalities in the access of secondary schooling, provide recent historical examples of social change that have been wrought though education, the result of 'collective decisions about the steering of a society' (Connell 2009, p. 226). Connell's (2009) historical overview of teaching notes that the profession has never been static, and that teaching is a complex assemblage of actions that cannot be reduced to 'tick a box' standards (or data points). Teaching is complex; it is an embodied activity, a form of emotional labour, and it is located within systems. It involves collective (rather than individual) labour and joint responsibility. While some facets of teaching are amenable to reduction via datafication, the aspects that make it profound are not. It is these aspects that offer points of resistance to the way that power is exercised in societies of control. As Connell (2012) makes clear, there are other forms of power in education: 'Education is dangerous, because schools and colleges do not just reproduce culture-they shape the new society that is coming into existence all around us' (p. 681).

We now turn our attention to the present, to consider the work of Biesta $(2010,2012)$ who is concerned with what it means to provide a 'good education', particularly in an era focused on the measurement of education outcomes. He offers a way to think and speak about the purposes of education that goes beyond the language of learning. With the 'learnification' of education and its focus on learning (as opposed to education more broadly), important questions about purpose, content and relationships become lost (Biesta 2010). For Biesta, education is multi-dimensional 
and the purposes of each of the different dimensions need to be determined for their specific educational context. The purposes that Biesta describe are: (i) qualification that is the way in which education qualifies people for doing things, by equipping them with knowledge skills and dispositions; (ii) socialisation-inducting students into cultures and professional orders; and (iii) subjectification-how education impacts on the person, how it affects their subjectivity (2010, pp. 19-21; 2012, pp. 1314).

Subjecting an educational future designed by Silicon Valley to a brief interrogation using Biesta's (2010) framework makes it easier to appreciate the impoverishment of this educational vision. In terms of qualification, it is possible that various knowledges and skills can be built into digital educational programs. Socialisation, as Williamson $(2017 \mathrm{a}, 2017 \mathrm{~b})$ has argued, is problematic (at least when we take ClassDojo as an example), as students are being socialised into particular Silicon Valley values: competition, entrepreneurship, surveillance, and technophilia. Debate is required about whether these represent the most suitable values for students outside Silicon Valley (or indeed inside Silicon Valley, for that matter). Similarly, students' subjectivities are not likely to develop positively when their behavior and achievements are constantly monitored, compared, assessed and gamified in competition with others (Lupton \& Williamson 2017, Williamson 2017b). While we have here only subjected a techno-educational future to a cursory critique, what we wish to make plain is that, although further interrogation is required, Biesta (2010) provides us with a useful model for asking necessary questions about the purposes of the educational activities taking place. Biesta (2012) challenges us to be 'educationally wise' and to maintain an education system that values teachers' capacity for educational judgement.

To conclude our exploration of the future of schooling on a perverse note, we follow Sellar's (2016) lead and argue that we need to leave the future behind. Sellar, in his discussion of educational research, traces the history of educational thought and argues that built into education is the idea that we are striving for the future, and that through education the future will be better. 'The affirmation of the future with which educational thinking begins encourages the alignment of optimistic dispositions and normative beliefs about the role of education in relation to opportunity in democratic, capitalist societies' (p. 14). Sellar (2016) suggests that this optimism can be a trap: 
Educational knowledge has bloomed with optimism, but this has produced a fragile and vulnerable monoculture. When confronted with the possibility that things are not getting better, educational research of all stripes resorts to prescribing more of the same in greater doses: we need better knowledge about how to make things better. (p. 13)

This optimism is built into policy, which is the political means by which we try to improve the system. It is also built in to practice, this belief that with more information, more data, we can improve the education system and through the education system improve lives. This constant quest for improvement, as Biesta (2010) has informed us, has led us down the path of measurement and datafication. Sellar's suggestion of leaving the future behind:

would not mean refusing the direction of time, but rather abandoning 'the future' as a psychological attitude with a relatively brief history. As a hopeful disposition toward a time to come, the future has provided a basis for modern educational thought: education is oriented by desire for progress. (2016, p. 13)

Sellar argues for alternatives to the idea of progress as a means of evaluating education. If we stop seeking progress as the goal and start to determine the value of education via other means, we will no longer be trapped in the thrall of future thinking. In Sellar's words: 'Leaving the future behind brings educational thought to the limit of this space and raises the question of escape' (2016, p. 13), and it is on this hopeful note of escape that we conclude.

\section{Conclusion}

In describing the current practices behind the datafication of education, it has been our purpose to sketch out the trajectory of these trends so that the future engendered by these can be considered. Pulling together a variety of contemporary research which explores these policies and practices, we have examined the datafication of teachers' work and of students' schooling. The potential role of Silicon Valley in designing the educational methods of the future was highlighted to flag the ideologies underpinning current trajectories. Further incursion of educational technologies into the classroom means that not just students' results but also their behaviours and mindsets become quantifiable sources of data. Students become more enmeshed in an 'ever-intensifying network of visibility, surveillance and 
normalization', where the 'embodied expert judgement' of their teachers is displaced by disembodied algorithmic and adaptive decision-making technology (Lupton \& Williamson 2017, pp. 7-8). The risk is that such processes shut down educational possibility and that students' prior actions determine the future learning made available to them. The algorithms that undergird such educational technologies are always based on past data, and not only limit students' opportunity based on the programming of those that design the products, but constrain future opportunity because of the inherent bias in the data upon which the calculations are based on. Reliance on such technologies also limits the opportunity for student-teacher relationships; without this relationality education is at risk of further alienating students. Deleuze (1992) provides a theoretical basis from which to consider contemporary educational dataveillance as a modality of control, as this work on the operation of power in societies of control also offers hope. For as Foucault has stated: 'As soon as there is a power relation, there is the possibility of resistance' (1989, p. 153). By invoking the past, present and future we have proffered three ways of philosophically considering alternatives to a datafied future of schooling.

\section{References}

Ball, S (1998) Big policies/small world: An introduction to international perspectives in education policy. Comparative Education, 34(2), pp. 119-130.

Ball, S (2012) Performativity, commodification and commitment: An I-Spy guide to the neoliberal university. British Journal of Educational Studies, 60(1), pp. 1728.

Biesta, G (2010) Good education in an age of measurement. Paradigm Publishers, Boulder, CO.

Biesta, G (2012) The future of teacher education: Evidence, competence or wisdom? Research on Steiner Education, 3(1), pp. 8-21

Clarke, M \& Moore, A (2013) Professional standards, teacher identities and an ethics of singularity. Cambridge Journal of Education, 43(4), pp. 487-500.

Connell, R (2009) Good teachers on dangerous ground: Towards a new view of teacher quality and professionalism. Critical Studies in Education, 50, pp. 213229. 
Connell, R (2012) Just education. Journal of Education Policy, 27(5), pp. 681-683.

Deleuze, G (1992) Postscript on the societies of control. October, 59, pp. 3-7. Available from: http://links.jstor.org/sici?sici=01622870\%28199224\%2959\%3C3\%3APOTSOC\%3E2.0.CO\%3B2-T

De Rosa, R (2017) Governing by data: Some considerations on the role of learning analytics in education. In N Lauro, E Amaturo, M Grassia, B Aragona \& M Marino (eds), Data science and social research. Studies in classification, data analysis, and knowledge organization. Springer, Cham., pp. 67-80.

Duff, AS (2016) Rating the revolution: Silicon Valley in normative perspective. Information, Communication and Society, 19(11), pp. 1605-1621.

Edwards, R \& Fenwick, T (2016) Digital analytics in professional work and learning. Studies in Continuing Education, 38(2), pp. 213-227.

Foucault, M (1989) The end of the monarchy of sex. Foucault Live. Semiotext(e), New York, NY.

Hartong, S (2018) Towards a topological re-assemblage of education policy? Observing the implementation of performance data infrastructures and 'centers of calculation' in Germany. Globalisation, Societies and Education, 16(1), pp. 134-150.

Lee, VR \& Drake, J (2013) Quantified recess: Design of an activity for elementary students involving analyses of their own movement data. In JP Hourcade, EA Miller \& A Egeland (eds), Proceedings of the 12th international conference on interaction design and children 2013. ACM, New York, NY, pp. 273-276.

Lee, VR, Drake, J \& Williamson, K (2015) Let's get physical: K-12 students using wearable devices to obtain and learn about data from physical activities. TechTrends, 59(4), pp. 46-53.

Lewis, S \& Holloway, J (2018) Datafying the teaching 'profession': Remaking the professional teacher in the image of data. Cambridge Journal of Education, 49, pp. 35-51.

Lupton, D (2016) The quantified self: A sociology of self-tracking. Polity Press, Cambridge. 
Lupton, D \& Williamson, B (2017) The datafied child: The dataveillance of children and implications for their rights. New Media \& Society, 19(5), pp. 780-794.

Mayer-Schoenberger, V \& Cukier, K (2013) Big data. A revolution that will transform how we live, work, and think. John Murray Publishers, London.

Ozga, J (2009) Governing education through data in England: From regulation to self-evaluation. Journal of Education Policy, 24(2), pp. 149-162.

Ozga, J (2016) Trust in numbers? Digital education governance and the inspection process. European Educational Research Journal, 15(1), pp. 69-81.

Ozga, J, Dahler-Larsen, P, Segerholm, C \& Simola, H (2011) Fabricating quality in education: Data and governance in Europe. Routledge, London.

Poster, M \& Savat, D (eds) (2009) Deleuze and new technology. Edinburgh University Press, Edinburgh.

Rizvi, F \& Lingard, B (2010) Globalizing education policy. Routledge, New York, NY.

Roberts-Holmes, G \& Bradbury, A (2016) The datafication of early years education and its impact upon pedagogy. Improving Schools, 19(2), pp. 119-128.

Robertson, SL (2005) Re-imaging and rescripting the future of education: Global discourses and the challenge to education systems. Comparative Education, 41(2), pp. 151-170.

Rosen, M (2018, February 8) Michael Rosen: The data have landed. Available from http://michaelrosenblog.blogspot.com/2018/02/the-data-have-landed.html

Savage, GC (2016) Who's steering the ship? National curriculum reform and the reshaping of Australian federalism. Journal of Education Policy, 31(6), pp. 833850.

Sellar, S (2015) A feel for numbers: Affect, data and education policy. Critical Studies in Education, 56(1), pp. 131-146.

Sellar, S (2016) Leaving the future behind. Research in Education, 96(1), pp. 12-18.

Sellar, S \& Lingard, B (2014) The OECD and the expansion of PISA: New global modes of governance in education. British Educational Research Journal, 40(6), pp. 917-936. 
Selwyn, N (2016) Is technology good for education? Polity, Cambridge.

Selwyn, N, Nemorin, S \& Johnson, N (2017) High-tech, hard work: An investigation of teachers' work in the digital age. Learning, Media and Technology, 42(4), pp. 390-405.

Stevenson, H (2017) The 'datafication' of teaching: Can teachers speak back to the numbers? Peabody Journal of Education, 92(4), pp. 537-557.

Thompson, G (2017) Computer adaptive testing, big data and algorithmic approaches to education. British Journal of Sociology of Education, 38(6), pp. 827-840.

Thompson, G \& Cook, I (2014) Manipulating the data: Teaching and NAPLAN in the control society. Discourse: Studies in the Cultural Politics of Education, 35(1), pp. 129-142.

Thompson, G \& Cook, I (2017) The logic of data-sense: Thinking through Learning Personalisation. Discourse: Studies in the Cultural Politics of Education, 38(5), pp. 740-754.

Williamson, B (2016a) Digital education governance: An introduction. European Educational Research Journal, 15(1), pp. 3-13

Williamson, B (2016b) Digital education governance: Data visualization, predictive analytics, and 'real-time' policy instruments. Journal of Education Policy, 31(2), pp. 223-141

Williamson, B (2017a) Educating Silicon Valley: Corporate education reform and the reproduction of the techno-economic revolution. Review of Education, Pedagogy, and Cultural Studies, 39(3), pp. 265-288.

Williamson, B (2017b) Decoding ClassDojo: Psycho-policy, social-emotional learning and persuasive educational technologies. Learning, Media and Technology, 43(4), pp. 440-453. 